\title{
ALIMENTAÇÃO SAUDÁVEL: PERCEPÇÕES DOS EDUCADORES DE INSTITUIÇÕES INFANTIS
}

\section{HEALTHY EATING HABITS: PERCEPTIONS OF CHILDCARE INSTITUTION EDUCATORS}

Assao TY, Cervato-Mancuso AMC. Alimentação Saudável: percepções dos educadores de instituições infantis. Rev Bras Crescimento Desenvol Hum. 2008; 18(2): 126-134.

Resumo: Objetivo: Analisar as percepções dos educadores sobre a alimentação saudável no âmbito escolar. Método: Estudo transversal de abordagem qualitativa no qual se utilizou o Discurso do Sujeito Coletivo (DSC), técnica_baseada nas representações sociais, que permitiu a organização e tabulação de dados de natureza verbal, obtidos por meio de entrevistas com 78 educadores de 8 instituições infantis públicas do município de Jandira, São Paulo. Resultados: A alimentação saudável para as crianças, sob o ponto de vista destes profissionais, foi percebida a partir de diferentes dimensões como: a variedade e a diversidade da alimentação; a quantidade e qualidade adequada, que atendesse às necessidades biológicas e às preferências alimentares; de consistência adequada, que fosse natural e oferecida nos horários certos. Muitos dos fundamentos que compõem uma alimentação saudável foram citados, porém verificou-se que algumas questões importantes não foram lembradas, como: a procedência e a preparação dos alimentos; a realização das refeições em ambientes calmos e a satisfação das necessidades emocionais e sociais. Ressaltando ainda que, dentre os itens contemplados, alguns apresentaram contradições e distorções, como as questões das preferências versus gostos alimentares e da consistência. Conclusão: A maioria das percepções dos educadores sobre a alimentação saudável observadas nos discursos demonstraram-se inadequadas quando comparadas aos parâmetros da promoção dos hábitos alimentares para as crianças. Práticas e percepções estas, que podem, em alguns casos, influenciar a conduta destes profissionais no momento das atividades de alimentação.

Palavras-chave: Alimentação; crianças; educadores; creches.

\section{INTRODUÇÃO}

A preocupação em promover uma alimentação saudável no ambiente escolar tem sido foco de atenção de políticas públicas relacionadas às áreas de saúde e de educação.

Nesta perspectiva, os Ministérios da Saúde e da Educação estabeleceram diretrizes con- siderando as recomendações da Estratégia Global para Alimentação Saudável, Atividade Física e Saúde da Organização Mundial da Saúde (OMS) e o desafio de incorporar o tema da alimentação e nutrição no contexto escolar, com ênfase na alimentação saudável e na promoção da saúde, reconhecendo a escola como um espaço propício à formação de hábitos sau-

\footnotetext{
Departamento de Nutrição. Faculdade de Saúde Pública. Universidade de São Paulo. São Paulo, SP, Brasil. Av. Dr. Arnaldo, 715, 01246-904 São Paulo, SP, Brasil. Fones/ Fax: (0xx11) 30617705. E-mail: tatiassao@usp.br Pesquisa financiada pela Fundação de Amparo à Pesquisa do Estado de São Paulo (FAPESP), processo 2006/00349-0. Tatiana Yuri Assao foi bolsista do Conselho Nacional de Desenvolvimento Científico e Tecnológico (CNPq), processo 135537/2005-3.

Artigo baseado na tese: Percepções e práticas sobre alimentação infantil entre os educadores de creches públicas. 2007. Dissertação de Mestrado. Faculdade de Saúde Pública. Universidade de São Paulo.
} 
dáveis e à construção da cidadania. Essas diretrizes nacionais foram instituídas para a promoção da alimentação saudável nas instituições de educação infantil, de ensino fundamental e médio das redes tanto públicas como privadas com o objetivo de propiciar a adesão da comunidade escolar a hábitos alimentares saudáveis e atitudes de auto cuidado e promoção da saúde. ${ }^{10}$

Dentre as ações propostas para nortear as diretrizes, destacam-se a sensibilização e capacitação dos profissionais envolvidos com alimentação das crianças na escola, para que estes ofereçam alimentos adequados e promovam ações a fim de que os escolares adquiram práticas alimentares saudáveis.

Estudos mostram que a base que sustenta a aprendizagem das crianças pequenas na escola depende do professor. $\mathrm{O}$ adulto deve ser o intermediador entre a criança, o objeto de sua ação, e o conhecimento. ${ }^{14} \mathrm{E}$ preciso facilitar contextos estimuladores que permitam à criança defrontar-se com novas experiências e nas quais possam aprender, experimentar, manipular e observar. No ambiente escolar é o educador quem auxilia as crianças no momento das refeições e, portanto ${ }_{2}$ o desenvolvimento do tema alimentação é de sua responsabilidade. $\mathrm{O}$ professor deve estabelecer situações que permitam que o menino ou a menina criem novos significados, com os quais poderão dar sentido às aprendizagens ${ }^{1}$.

Neste sentido, além de verificar a composição das refeições, o tamanho das proporções dos alimentos oferecidos para a criança, a hora e o local onde serão realizadas as refeições, é necessário conhecer as possíveis divergências de entendimento entre as pessoas envolvidas com a alimentação, sejam elas_pais, avós e/ou educadores. ${ }^{19}$ Assim, este estudo objetivou identificar e analisar as percepções dos educadores de instituições infantis de um município do estado de São Paulo sobre a alimentação saudável no ambiente escolar.

\section{MÉTODO}

Trata-se de um estudo transversal com abordagem qualitativa, ou seja, aquela capaz de incorporar a questão do significado e da intencionalidade como inerentes aos atos, às relações e às estruturas sociais, como construções humanas significativas. ${ }^{8}$ Utilizou-se este tipo de abordagem a fim de tornar mais clara a compreensão das representações, das percepções e dos valores que envolvem estes profissionais e o tema da alimentação saudável infantil.

Participaram do estudo os professores de crianças de 2 a 4 anos das oito instituições de educação infantil sob administração direta da prefeitura do município de Jandira. Este município está localizado a 30km da cidade de São Paulo, com uma população estimada em 109.782 habitantes distribuída em $18 \mathrm{~km}^{2}$ de área. ${ }^{12}$

Foram selecionados os professores que, no momento da pesquisa, trabalhavam com o Maternal I (crianças de 2-3 anos) e Maternal II (crianças de 3-4 anos). Foram excluídos da amostra os professores que não permaneciam fixos no cargo $(3,0 \%)$; aqueles que se encontravam em período de licença saúde ou maternidade $(4,1 \%)$; além daqueles que após duas tentativas se recusaram a participar da pesquisa $(14,1 \%)$. Assim, de dezembro de 2005 a março de 2006, foram entrevistados 78 educadores, ou seja, $78,8 \%$ dos profissionais do município que trabalhavam com crianças do grupo etário alvo do estudo.

Para a coleta dos dados, utilizou-se a entrevista individual baseada em um roteiro semiestruturado, no qual o sujeito entrevistado tinha a possibilidade de expor suas opiniões em relação ao tema proposto, sem respostas estabelecidas. $^{8}$

Para se ter o depoimento em sua integralidade, utilizou-se a gravação magnética, com posterior transcrição fidedigna das respostas.

O local da entrevista foi reservado, tendo em vista a técnica utilizada e que as informações reveladas não poderiam ser compartilhadas com outros profissionais, pois poderiam induzir as respostas do professor não entrevistado ou mesmo gerar constrangimentos e não permitir o sigilo das opiniões.

Para a organização e análise dos depoimentos das entrevistas utilizou-se a técnica do Discurso do Sujeito Coletivo (DSC) ${ }^{7}$ e o suporte 
do software Qualiquantisoft versão 1.3c. ${ }^{7}$

A técnica do DSC constitui um recurso metodológico que permite uma forma não-matemática e nem metalingüística de representar o pensamento de uma coletividade, ou seja, uma dada representação social. ${ }^{6}$ As representações sociais são sistemas de interpretação que regem nossas relações com o mundo e com os outros, orientam e organizam as condutas e as comunicações sociais, elas intervêm da difusão e da assimilação dos conhecimentos, do desenvolvimento individual e do coletivo, da definição das identidades pessoais e sociais, da expressão dos grupos e das transformações sociais. ${ }^{5}$

Nesta técnica, as opiniões convergem em um conjunto de discursos coletivos, ou DSCs, que é um processo realizado mediante uma série de operações sobre o material verbal coletado nas pesquisas. ${ }^{6}$ Após a transcrição literal dos depoimentos, partiu-se dos discursos em estado bruto para o trabalho analítico de decomposição, que consiste na seleção das figuras metodológicas (expressões chaves e idéias centrais) presentes em cada um.

O DSC é redigido na primeira pessoa do singular, com a finalidade de marcar expressivamente a presença do pensamento de um sujeito que fala em nome de uma coletividade. ${ }^{7}$ Assim, numa pesquisa, cada questão aberta a ser respondida por uma dada amostra da população, pode gerar um número variado de diferentes posicionamentos, ou seja, um número variado de DSC, que podem ser distintos tanto do ponto de vista qualitativo, na medida em que veiculam opiniões diferentes, como do ponto de vista quantitativo, uma vez que cada DSC é resultado da contribuição de um certo número de depoimentos de indivíduos portadores de determinados atributos. ${ }^{6}$

Nesta pesquisa considerou-se, em todas as suas etapas, os princípios éticos fundamentais que norteiam pesquisas envolvendo seres humanos, descritos e estabelecidos pela Resolução CNS 196/96. O projeto da presente pesquisa foi apresentado e aprovado pelo Comitê de Ética em Pesquisa da Faculdade de Saúde Pública da Universidade de São Paulo. Os educa- dores, que concordaram em participar deste trabalho, preencheram e assinaram o Termo de Consentimento Livre e Esclarecido. E o Termo de Autorização da Pesquisa foi assinado pelo Departamento de Educação de Jandira.

\section{RESULTADOS}

Dentre os indivíduos estudados, observouse predominância dos profissionais do sexo feminino (93,6\%); do grupo etário de 20 a 30 anos $(30,8 \%)$; com filhos $(76,9 \%)$; sem uma formação específica na área da educação $(51,3 \%)$; com experiência anterior em creches e/ ou escolas de diferentes níveis de ensino (41,0\%), que participaram dos cursos de formação continuada promovidos pela prefeitura do município $(98,7 \%)$.

As representações acerca da alimentação saudável para as crianças, ou seja, os resultados dos depoimentos dos educadores são apresentados por meio de Idéia Central (IC) e Discurso do Sujeito Coletivo (DSC). ${ }^{7}$

Foram identificadas 94 expressões chaves que compuseram as 10 ICs e seus respectivos DSCs, representando o entendimento da população estudada em relação ao conceito da alimentação saudável para as crianças (Tabela 1).

Considerando que neste estudo realizouse uma análise qualitativa, deve-se mencionar que os resultados quantitativos referem-se ao número ou percentual de respostas de pessoas, que contribuíram com expressões para a constituição de um discurso, entendido como um desdobramento de uma idéia em seus conteúdos e argumentos correspondentes. ${ }^{7}$ Desta maneira, os dados apresentados em gráfico referem-se mais precisamente à freqüência de respostas que contribuíram para a construção de um DSC.

Na Figura 1, constata-se uma maior citação da idéia que refere a alimentação saudável como aquela que oferece o essencial às crianças como o arroz, feijão, carnes, verduras, legumes e frutas, representado pela IC-A $(18,0 \%)$. Enquanto com um menor destaque encontra-se a IC-J $(3,2 \%)$, que a descreve como sendo aquela alimentação semelhante à do adulto. 
Tabela 1. Discursos do Sujeito Coletivo referente às percepções dos educadores sobre alimentação saudável para crianças, segundo as idéias centrais. Jandira, 2006.

Idéia Central (IC)
IC-A: É o essencial:
arroz, feijão, carnes, verduras,
legumes e frutas.
legumes e frutas.

IC-B: Não ter sempre a mesma coisa.

IC-C: Muitas verduras e legumes, as crianças nesta idade não sabem comer, mas é preciso ensinar.

IC-D: Balanceada, nem em excesso e nem faltando.

IC-E: Uma alimentação que a criança come e gosta.

IC-F: Aquela que tivesse todos os nutrientes que elas precisam.

IC-G: Uma boa alimentação horários certos.

IC-H: Deveria ser tudo natural.

IC-I: O leite, que é indispensável.

IC-J: Uma alimentação quase que nem do adulto.

\section{Discurso Sujeito Coletivo (DSC)}

DSC-A: Uma alimentação que envolvesse o essencial:arroz, feijão, carne, fígado, frango, salsicha, peixe,verduras, legumes, saladas, frutas, suco de frutas sempre natural,cereais, macarrão, para crianças de 2 a 4 anos também leite.... o que a criança come mesmo, isso que é fundamental. Eles deveriam comer de tudo um pouco. Se a criança comer isso ela está bem alimentada. Acho que dentro do que seria saudável é isso.

DSC-B: Conter o necessário para criança se desenvolver, muita variedade. Tem que ser diferenciada, não ter tanta repetição, não ter sempre a mesma coisa, um dia uma coisa e outro dia outra, ter um cardápio que envolva vários tipos de alimentos. Eles acabam enjoando da mesma coisa: "vou comer carne de novo!", vou comer salada de tomate de novo!". Tem que ter legumes, frutas e carnes diversas. Na segunda faz uma alimentação, na terça faz outra. A variedade é o que importa num cardápio de uma criança.

DSC-C: É aquela enriquecida com verduras e legumes. O arroz e feijão também, mas dar mais prioridade aos legumes. Seria o ideal para eles (mas) eles têm dificuldade de ver e comer. Geralmente eles gostam do básico, alface e tomate, deveria dar mais verduras diferentes, ter mais o hábito de outras verduras e frutas. As crianças, geralmente, nesta idade não sabem comer frutas e legumes, mas nós precisamos ensinar. Acredito que seja isso.

DSC-D: Uma alimentação balanceada que tenha de tudo um pouco, nem em excesso e nem faltando. Massas, leite, carne vermelha ou branca, rica (em) frutas e verduras, uma salada colorida que chame atenção das crianças e de sobremesa um suco ou uma fruta. Uma alimentação sem muito sal, sem muita gordura, sem muito tempero, bem cozida e geralmente nada de fritura, não seria pesada, não conteria muito doce, balas, pouco açúcar, menos refrigerante, salgadinhos, essas porcarias. Elesgostam também das besteirinhas, mas com moderação...

DSC-E: Uma alimentação enriquecida e equilibrada, mas que também possa atingir a expectativa da criança no paladar. É uma refeição bem feita que a criança come e gosta. É aquela comida bem temperada e bem cozida (porque) eles não sabem mastigar muito bem, comida meio crua não fica legal, não faz. bem. Para 2 a 4 anos deveria ser uma coisinha mais leve. Uma comida mais líquida porque sólida as crianças não come, não conseguem comer ainda.

DSC-F: Uma alimentação que suprisse as carências e as necessidades das crianças, que tivesse um pouco de todos os nutrientes que elas precisam, com todo tipo de vitaminas, minerais, proteínas e carboidratos. A criança precisa de ferro, de cálcio, fibras... de um monte de coisas, a fase delas é de crescimento.

DSC-G: É uma comida balanceada, mas nos horários certos. O café-da-nos manhã bem reforçado; no meio uma fruta; depois o almoço com arroz, feijão, salada, verduras, carnes, legumes variados e frutas; à tarde, um lanchinho; a janta e às vezes um leite à noite.

DSC-H: É uma alimentação natural, desde sucos de fruta, com vegetais, bem verduras de todos os tipos, sem porcarias. O suco, não artificial que eu acho um absurdo. Eu sou pobre, mas nunca dei esses sucos para minhas filhas. As verduras tiradas diretamente da horta. Deveria ser tudo bem natural para as crianças, tudo fresquinho e limpinho. A comida natural é uma alimentação saudável.

DSC-I: O leite primeiramente, que é muito importante para as crianças, não pode faltar, tem que ter, é indispensável para eles.

DSC-J: Eles já podem ter uma alimentação quase que nem do adulto, são os alimentos sólidos... já que estão aprendendo a mastigar. Não é aquela comida triturada, a criança tem que exercitar a dentição, então você não pode acostumar a criança comer só aquele alimento triturado.

Fonte: Creches públicas do município de Jandira, São Paulo, 2006. 
Figura 1. Distribuição da proporção $(\%)$ das idéias centrais referentes às percepções dos educadores sobre alimentação saudável para crianças. Jandira, 2006.

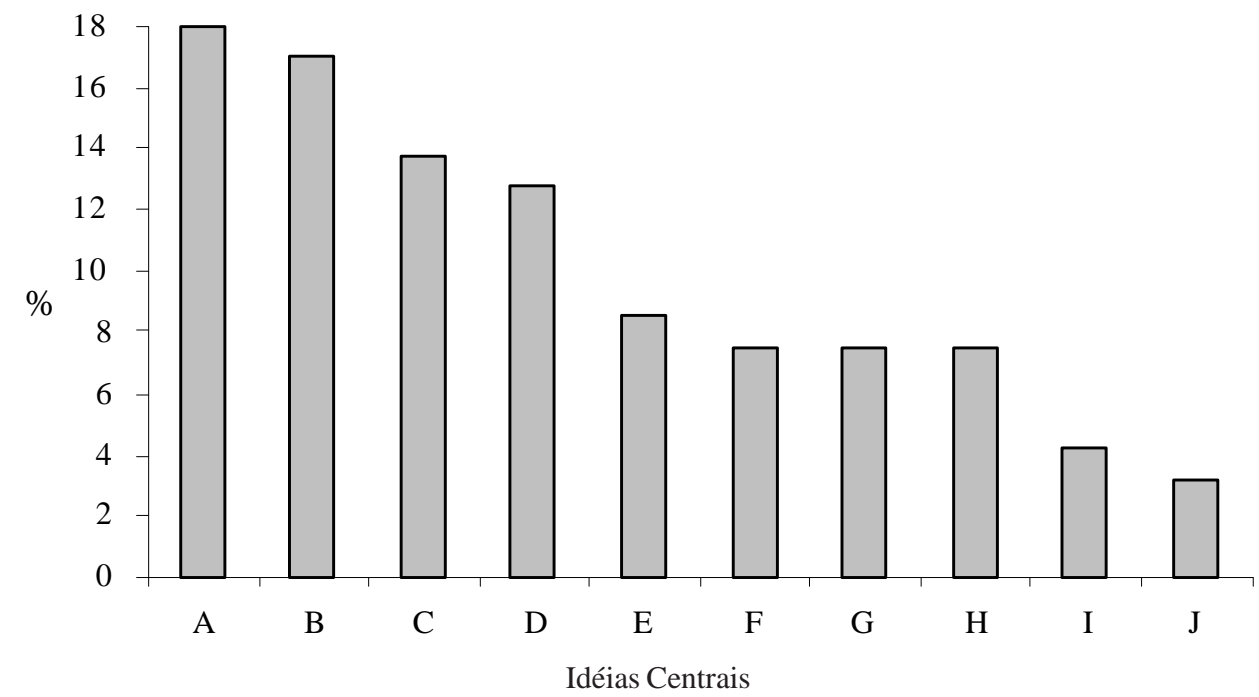

Fonte: Creches públicas do município de Jandira, São Paulo, 2006.

Legenda:

Idéias Centrais

A-É o essencial: arroz, feijão, carnes, verduras, legumes e frutas

B -Não ter sempre a mesma coisa.

C-Muitas verduras e legumes, as crianças nesta idade não sabem comer, mas é preciso ensinar

D-Balanceada, nem em excesso e nem faltando.

E-Uma alimentação que a criança come e gosta.

$\mathrm{F}$-Aquela que tivesse todos os nutrientes que elas precisam.

G-Uma boa alimentação nos horários certos.

$\mathrm{H}$-Deveria ser tudo bem natural.

I-O leite, que é indispensável.

$\mathrm{J}$-Uma alimentação quase que nem do adulto.

\section{DISCUSSÃO}

Dentre as ICs identificadas que resultaram nos DSCs, destacam-se algumas percepções relevantes, como as que abordam a questão da variedade na alimentação, da diversidade, do papel antagônico dos alimentos e nutrientes e as preferências alimentares.

Quanto à percepção relacionada à variedade, verifica-se no DSC-A a preocupação em oferecer os "alimentos essenciais", ou seja, aquela que contempla os alimentos fundamentais, mas que pertencem aos diferentes grupos, não se limitando a um tipo de alimento, isto é, uma alimentação variada, como os princípios estabelecidos pelo MINISTÉRIO DA SAÚDE ${ }^{9}$ (2006): consumo de vários tipos de alimentos que fornecem diferentes nutrientes necessários para atender às demandas fisiológicas e garantir a alimentação adequada.

Esta percepção de variedade é complementada pelos depoimentos que construíram o DSC-B, que entende a alimentação saudável como aquela diversificada, não se restringindo apenas à variedade, mas que em de cada grupo os alimentos existam em diferentes itens. "Eles acabam enjoando... Vou comer salada de tomate de novo! Tem que ter legumes, frutas e carnes diversas...". Esta abordagem também está presente no DSC-C, "deveria dar mais verduras diferentes, ter mais o hábito de outras verduras e frutas... muitas verduras e legumes, as crian- 
ças nesta idade não sabem comer, mas é preciso ensinar". O documento do MINISTÉRIO DA SAÚDE $^{9}$ (2006) também aborda o aspecto da diversidade dietética, como um pressuposto do conceito da alimentação saudável.

Ressalta-se uma diferença entre os conceitos proferidos pelos indivíduos que contribuíram para a construção destes discursos. No DSC$\mathrm{B}$, nota-se um conceito ideal, no qual os educadores definem a alimentação saudável para as crianças como variada e principalmente diversificada, enquanto o DSC-A representa um conceito baseado na realidade da alimentação oferecida nestas instituições, que segundo os profissionais entrevistados, apesar de variada (conter todos os grupos alimentares) não é diversificada, tratando-se de uma alimentação repetitiva em que as crianças facilmente enjoam e isso não deveria acontecer, pois não é "saudável".

Vale ressaltar ainda, a abordagem centrada na "figura dos alimentos" e não nos "nutrientes". As necessidades nutricionais das crianças, neste caso, deveriam ser atendidas pelos alimentos, pela comida. Este entendimento é o mesmo presente no documento do MINISTÉRIO DA SAÚDE$^{9}$ (2006), que aponta a alimentação em função do consumo de alimentos e não de nutrientes. Neste documento, uma alimentação saudável deve estar baseada em práticas alimentares que tenham significado social e cultural.

PROENÇA e POULAIN ${ }^{13}$ (2007) destacam que a alimentação participa da construção e da manutenção das identidades sociais no sentido de que o ser humano come os nutrientes, mas também come os sinais e os símbolos daquilo que os alimentos representam. Assim, semelhantemente, os educadores percebem que as crianças deveriam consumir somente os alimentos que lhes são carregados de significados, ou seja, embora fisiologicamente possam comer diferentes substâncias (vegetais, minerais e animais), elas comerão somente aquilo que reconhecem como alimento (DSC-A e B).

Diferente destas representações, o DSC$\mathrm{F}$ valoriza os nutrientes. Este discurso concebe a alimentação saudável numa dimensão biológica como aquela que inclui os nutrientes que as crianças necessitam. SILVA et al. ${ }^{16}$ (2002) em um estudo sobre a concepção da alimentação saudável com profissionais da saúde, também se depararam com este pensamento que percebe a alimentação saudável como uma soma de nutrientes, consequiência da racionalização do pensamento científico que tem valorizado o organismo e não o conteúdo humano e cultural, levando a crer que o corpo se alimenta de nutrientes e não de alimentos. Neste sentido, o Guia Alimentar para População Brasileira do MINISTÉRIO DA SAÚDE ${ }^{9}$ (2006) entende a alimentação saudável de forma dualista. Inicialmente, concebe a alimentação saudável, como aquela que deve fornecer água, carboidratos, proteínas, lipídios, vitaminas, fibras e minerais, os quais são insubstituíveis e indispensáveis ao bom funcionamento do organismo. Entretanto, este mesmo Guia, no seu conteúdo, reforça a importância de se respeitar os valores culturais, sociais, emocionais e comportamentais dos alimentos. Deve-se considerar, todavia, que esta percepção biológica esteve presente em poucos depoimentos do grupo estudado, prevalecendo a figura do alimento como o símbolo da alimentação saudável.

Em outros depoimentos nota-se a representação da alimentação adequada como aquela que evita os excessos (DSC-D). Ao mesmo tempo em que existe uma apreensão para que numa alimentação saudável as crianças consumam todos os tipos de alimentos, existe outra para que se evite alguns. _Verifica-se, assim a preocupação tanto com a qualidade quanto com a quantidade da ingestão de certos tipos de alimentos. Estes significados também apareceram nas percepções do estudo realizado por SILVA et al. ${ }^{16}$ (2002) entre profissionais da área de saúde da região metropolitana do Distrito Federal.

Outra percepção da alimentação saudável diz respeito à "alimentação que a criança come e gosta", apresentado no DSC-E. Neste discurso, os educadores indicam que a alimentação saudável é aquela que respeita as preferências alimentares das crianças. Seguindo esta abordagem, o DSC-C também se foca na questão das preferências alimentares, porém referindo-se à alimentação saudável como aquela em que é preciso estimular e ensinar a criança a comer mesmo que elas ainda não gostem de al- 
guns alimentos: "muitas verduras e legumes, as crianças nesta idade não sabem comer, mas é preciso ensinar".

Apesar destes discursos (DSC-E e C) destacarem a questão do comportamento alimentar, pode-se observar uma contradição entre eles: um respeita as preferências e gostos das crianças e não insiste no oferecimento dos alimentos e o outro continua estimulando para que adquiram novos gostos e conseqüentemente novas preferências alimentares. De acordo com BIR$\mathrm{CH}^{2}$ (1992), a segunda conduta seria a mais adequada, visto que o aumento da aceitação a um alimento ocorre somente após aproximadamente 12 a 15 apresentações do alimento à criança.

Para alguns pesquisadores o hábito alimentar não é, necessariamente, sinônimo de preferências alimentares, mas no caso específico dos pré-escolares este entendimento nem sempre é válido. As crianças desta faixa etária acabam consumindo somente alimentos de que gostam, entre os disponíveis no seu ambiente, refutando aqueles de que não gostam..$^{3,18}$

Ainda no DSC-E, os educadores também descreveram as preferências alimentares das crianças quanto às consistências "também bem cozida (porque) eles não sabem mastigar muito bem... Uma comida mais líquida porque sólida as crianças não come, não conseguem comer ainda". Esta percepção é contestada por alguns pesquisadores como SILVEIRA e GOLDENBERG. ${ }^{17}$ Estes autores apontam que não se deve incentivar tal hábito, pois quando uma dieta alimentar de consistência branda/pastosa é consumida frequientemente na infância, pode-se levar a falta da capacidade muscular da função mastigatória, criando uma tendência para a escolha de alimentos menos fibrosos ou duros, assim a musculatura perderia ainda mais sua capacidade, gerando um círculo vicioso.

Desta maneira, recomendações para uma alimentação infantil adequada destacam a importância na distinção entre a alimentação do lactente e da criança no segundo e outros anos de vida. Conforme a criança vai crescendo e se desenvolvendo, a alimentação deve progressivamente sofrer modificações, principalmente em relação à forma de preparação, ao tipo de ali- mentos utilizados e à consistência da comida. ${ }^{15}$

Outras pesquisas sobre este tema ainda afirmam que a consistência inadequada dos alimentos compromete a ingestão adequada de nutrientes pela criança, por isso no início da alimentação complementar recomenda-se a inclusão de alimentos semi-sólidos e macios. Sopas e comidas ralas e moles não fornecem energia suficiente para suprir às necessidades das crianças e devem ser desaconselhadas. A consistência deve ser aumentada gradativamente, respeitando as habilidades das crianças. ${ }^{4} \mathrm{E}$ a partir de um ano de idade, a criança já está apta a receber a alimentação normal da família. ${ }^{20}$ Estes conceitos contrapõem-se ao citado no DSC$\mathrm{E}$, mas são compartilhados pelos educadores que contribuíram para a construção do DSC-J. Estes educadores definem a alimentação saudável como quase semelhante à do adulto, ou seja, os alimentos devem ser oferecidos em consistência sólida, visto que são crianças de 2 a 4 anos.

Assim, identificou-se que a alimentação saudável para crianças sob o ponto de vista dos educadores é percebida a partir de diferentes dimensões, como a questão da variedade e diversidade da alimentação; da quantidade e qualidade adequada, que atenda às necessidades biológicas e às preferências alimentares; de consistência adequada, que seja natural e oferecida nos horários certos. Estas percepções também estão englobadas na definição proposta por PHILIPPI et al. ${ }^{11}$ (2000): "Alimentação saudável é aquela planejada com alimentos de todos os tipos, de procedência conhecida, de preferência natural e preparada de forma a preservar o valor nutritivo e os aspectos sensoriais". Os alimentos devem ser qualitativa e quantitativamente adequados, do hábito alimentar, consumido em refeições, em ambientes calmos, visando a satisfação das necessidades nutricionais, emocionais e sociais, para promoção de uma qualidade de vida saudável". Os educadores citaram grande parte dos itens que compõem uma alimentação saudável, mas pode-se verificar que nem todos foram contemplados, como a questão da procedência, a forma de preparação, os ambientes calmos e a satisfa- 
ção das necessidades emocionais e sociais. E dentre os itens contemplados alguns divergiam dos parâmetros propostos por estudos e documentos existentes na área. Destacando-se o discurso que aborda a questão das preferências alimentares, confundida com o ato de oferecer somente os alimentos que as crianças gostam, ato não adequado para este grupo, pois ainda se encontram em fase de conhecimento dos diferentes gostos alimentares. Outra divergência importante refere-se à consistência dos alimentos. Verificou-se que alguns profissionais aliam a imagem das "crianças pequenas" aos alimentos de consistência pastosa e líquida, porém neste grupo etário é adequado oferecer alimentos mais consistentes, muito próximos aos utilizados pela família. ${ }^{20}$

\section{CONCLUSÃO}

Os discursos revelam que os principais fundamentos de uma alimentação saudável foram incorporados. Por outro lado, alguns aspectos, como a questão das preferências versus gostos alimentares e da consistência, ainda apresentam contradições e distorções em relação às recomendações nutricionais.

Desta forma, as percepções dos educadores acerca da alimentação infantil ainda demonstraram-se inadequadas quando comparadas aos parâmetros da promoção dos hábitos alimentares para as crianças do grupo etário estudado. Práticas e percepções estas, que poderiam em alguns casos influenciar a conduta destes profissionais no momento das atividades de alimentação.

\begin{abstract}
Objective: To assess educators' perceptions of healthy eating habits within an educational environment. Methods: Cross-sectional qualitative study in which the Collective Subject Discourse (CSD) was used, a methodology based on social representations that enabled organizing and arranging verbal qualitative data, obtained through interviews with 78 educators from eight public childcare centers in the municipality of Jandira, São Paulo. Results: Healthy eating habits for children, according to such professionals, were perceived from different perspectives, such as: the issue of a varied and diversified diet; adequate quantity and quality, meeting both biological needs and food preferences; appropriate consistency, natural feature, and provided at right times. Much of the foundations of a healthy diet were mentioned; however, some important issues were not recalled, like food origin and preparation, having meals in calm environments and meeting emotional and social needs. Furthermore, among the listed items, some were contradictory and distorted, such as food preferences as compared to food likings and consistency. Conclusion: Most educators' perceptions about children's healthy eating habits, as observed from their discourse, still are deficient as compared to parameters designed to promote healthy eating practices for children. Such practices and perceptions could, in some cases, have an impact on the behavior of such professionals while performing eating activities.
\end{abstract}

Keywords: Feeding; children; educators; day-care centers.

\section{REFERÊNCIAS}

1. Bassedas E, Huguet T, Solé I. Aprender e ensinar na educação infantil. Porto Alegre: Artes Medicas; 1999. p.21-27.

2. Birch LL. Children's preferences for high fat foods. Nutr Rev. 1992; 50: 249-55.

3. Birch LL. Psychological influences on the childhood diet. J Nutr. 1998; 128: 407S-10S.

4. Giugliani ERJ, Monte CMGM. Recomendações para alimentação complementar da criança em aleitamento materno. J Pediatr. 2004; 80(5):
S131-S141.

5. Jodelet D. As representações sociais. Rio de Janeiro: UERJ; 2001. p.17-44.

6. Lefèvre F, Lefèvre AMC. Depoimentos e discursos: uma proposta de análise em pesquisa social. Brasília: Líber Livros; 2005. p.13-27.

7. Lefèvre F, Lefèvre AMC. Discurso do sujeito coletivo: um novo enfoque em pesquisa qualitativa (desdobramentos). Caxias do Sul: EDUCS; 2003. p.13-46.

8. Minayo MCS. O desafio do conhecimento: 
pesquisa qualitativa em saúde. São Paulo: Hucitec; 1992. p.10, 120-127.

9. Ministério da Saúde. Secretaria de Atenção à Saúde. Departamento de Atenção Básica. Coordenação Geral da Política de Alimentação e Nutrição. Guia alimentar para população brasileira: promovendo a alimentação saudável. Brasília (DF): MS; 2006. p.15-44.

10. Ministério da Saúde/ Ministério da Educação. Portaria interministerial $\mathrm{n}^{\circ} 1.010$ de 8 de maio de 2006 [homepage na internet]. Brasília; 2006. Disponível em URL: http:// dtr2004.saude.gov.br/sas/legislacao/ portaria1010_08_05_06.pdf [2007 maio 15].

11. Philippi ST, Colucci ACA, Cruz ATR, Ferreira MN, Coutinho RLR. Alimentação saudável na infância e na adolescência. In: Silva MV, organizador. Curso de atualização em alimentação para professores de rede pública de ensino. Piracicaba: Escola Superior de Agricultura Luiz de Queiroz (Esalq); 2000. p.4656.

12. Prefeitura do Município de Jandira [homepage na internet]. São Paulo; 2007. Disponível em URL: http://www.jandira.sp.gov.br [2007 abr 15].

13. Proença RPCP, Poulain J. Sociologia da alimentação: um enfoque na compreensão dos comportamentos alimentares. In: Taddei JAAC, coordenador. Jornadas científicas do Núcleo Interdepartamental de Segurança Alimentar e
Nutricional. Barueri: Manole; 2007. p.165-178.

14. Rizzo G. Creche: organização, currículo, montagem e funcionamento. Rio de Janeiro: Bertrand Brasil; 2000. p.121-133.

15. Rotenberg S, Vargas SD. Práticas alimentares e o cuidado da saúde: da alimentação da criança à alimentação da família. Rev Bras Saúde Materno Infat. 2004; 4(1): 85-94.

16. Silva DO, Recine EGIG, Queiroz EFO. Concepções de profissionais de saúde da atenção básica sobre a alimentação saudável no Distrito Federal, Brasil. Cad Saúde Pública. 2002; 18(5): 1367-1377.

17. Silveira LDBR, Goldenberg M. Hábitos e preferências alimentares de crianças com três a cinco anos de idade. Pró-Fono Rev Atual Cient. 2001; 3: 37-44.

18. Stein LM, Ramos M. Desenvolvimento do comportamento alimentar infantil. J Ped. 2000; 76(3): 229S-237S.

19. Vieira MNCM, Santos GVB, Resende CMM. Nutrição da criança pré-escolar e escolar. In: Monteiro JP, Júnior JSC. Nutrição e metabolismo: caminhos da nutrição e terapia nutricional da concepção à adolescência. Rio de Janeiro: Guanabara Koogan; 2007. p. 278310.

20. Vitolo M. Nutrição: da gestação à adolescência. Rio de Janeiro: Reichmann \& Affonso Editores; 2003. p.145-151.

Recebido em: 22/02/2008

Modificado em: 15/06/2008

Aprovado em: 30/08/2008 